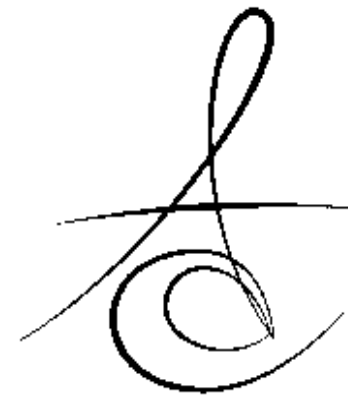

Makale Kodu/Article code: 1067

Makale Gönderilme tarihi: 30.01.2013

Kabul Tarihi; 30.01.2013

\section{KEMOTERAPİYE BAĞLI MUKOZİT}

\section{MUCOSITIS RELATED TO CHEMOTHERAPY}

\author{
Doç.Dr. İlhami KİKí *
}

\section{ÖZET}

Kemoterapiye bağlı mukozit, sistemik kemoterapinin kişiye sınırlı bir kopmplikasyonudur. Esas olarak hızlı bölünen epitelyal hücrelerin kemoterapi tarafından uyarılan hasarı ve reaktif oksijen radikallerinin artması ve salınması sonucu gelişir. Oral beslenmeyi bozmasının yanı sıra mukozit aynı zamanda mikrobiyal ajanlara karşı mukozal bariyerin bozulması nedeniyle sistemik bakteriyemi, fungemi ve viremiye de yol açabilir. Her ne kadar çeşitli profilaktik ve terapötik yaklaşımlar mevcut olsa da bunlardan çoğu etkin değildir. Risk değerlendirmesi ve etkin önleyici tedavi gereklidir.

Anahtar Kelimeler: Kemoterapi, Mukozit

\section{ABSTRACT}

Chemotherapy induced mucositis is a self-limited complication of systemic chemotherapy. It is mainly due to the chemotherapy induced DNA damage of rapidly dividing epithelial cells and release and upregulation of reactive oxygene radicals. In addition to interfering oral nutrition, mucositis can also leads to systemic bacteriemia fungemia and viremia due to the destruction of mucosal barrier against microbial agents. Although, several prophylactic and therapeutic approaches are available, most of them are ineffective. Risk assesment and effective preventive treatment is mandatory.

Keywords: Chemotherapy, mucositis

\section{GİŖ̇}

Kanser tedavisinde hem akut hem de kronik oral toksisite sık gözlenir. akut toksisiteler arasında mukozit, tükrük değişiklikleri, tat değişiklikleri, enfeksiyon ve kanama, geç toksisiteler arasında ise mukozal atrofi ve xerostomi sayılabilir. ${ }^{1}$

Mukozit: Kemoterapinin kişiye sınırlı yan etkisi olup tüm gastrointestinal sistemi etkileyebilir ve kemoterapi ve/veya radyoterapi alan hastalarda önemli bir sorundur. Semptomlar oral ülserasyon, disfaji, odinofaji, diyare ve malabsorbsiyon tarzında olabilir. $^{2}$ Sitotoksik kemoterapi uygulanan hastaların \%35-40 ında mukozit görülür. ${ }^{3}$ Özellikle hazırlama rejiminde radyoterapi uygulanan allogeneik kök hücre transplantasyon hastalarında mukozit hem daha sık hem de daha ağırdır. ${ }^{4}$
Mukozal bariyerin kemoterapite bağlı hasarlanma mekanizması karmaşıktır. Gerek kemoterapi gerekse radyoterapi hem DNA hasarı oluşturarak hem de DNA dışı hedefleri direkt etkileyerek serbest oksijen radikali oluşumunu uyarır. Bu uyarı sonucunda çeşitli proinflamatuar sitokinlerin yapımı artar. Sonuçta doku hasarı ve ülserasyon gelişir ve mukoza bakteriyel kontaminasyona açık hale gelir. ${ }^{3}$

Risk Faktörleri: Mukozit gelişimi ve derecesi gerek kullanılan ilaca, gerek verilen doza gerekse hastanın toleransına göre değişkenlik gösterir.özellikle DNA siklusuna özgün kemoterapötik ajanlar daha fazla mukozite neden olur. Bunların arasında;

- Bleomisin

- Etoposid

- 5 fluorourasil

- Metotreksat ve

- $\quad$ Doksorubisin sayılabilir. ${ }^{5}$

\footnotetext{
**Atatürk Üniversitesi Tıp Fakültesi İç Hastalıkları Anabilim Dalı Hematoloji Bilim Dalı/ERZURUM
} 
Tedavi öncesi oral hastalık (kötü hijyen, çürükler ve periapikal patolojiler, periodontal hastalık) varlığının kemoterapiye bağı mukoziti artırdığı düşünülmektedir. ${ }^{6}$ Keza baş ve boyun bölgesine

Kemoterapötik ajanlar özellikle hızlı çoğalan hücreler üzerine toksik etki yapar. Genç hastalarda mukozal mitoz hızının yüksek olmasına bağlı mukozit gelişimi daha sıktır. Genetik yatkınlığın rolü henüz kanıtlanamamıştır.

Klinik Belirtiler: Genellikle tedaviden sonraki 1 haftada stomatotoksisite pik yapar. Mukozitin derecesi ağızda hafif yanmadan ciddi eroziv ülserlere ve oral beslenememeye kadar değişebilir. Başlangıçta yumuşak dokuda eritem gözlenirken zamanla düzenli sınırlı kabarık beyaz plaklar ve mukozal soyulmaya bağlı yüzeyel ülserler görülür. Birlikte görülen nötropeni de bu bölgelerden bakteriyel kontaminasyon ve sepsis gelişimine zemin hazırlar Mukozit genellikle kendi kendini sınırlar ve genellikle 10-14 gün içinde düzelir. 1,5,7,8

Mukozit Evrelemesi: En sık kullanılan kriterler National Cancer Institute Common Terminology kriterleridir. ${ }^{9}$

Tablo 1. Mukozit evrelemesi

\begin{tabular}{|l|l|}
\hline Evre 1 & $\begin{array}{l}\text { Asemptomatik veya hafif semptomlar. } \\
\text { Müdahaleye gerek yok. }\end{array}$ \\
\hline Evre 2 & $\begin{array}{l}\text { Orta derecede ağrı, beslenmeyi bozmuyor. } \\
\text { Diyet modifikasyonu gerekli }\end{array}$ \\
\hline Evre 3 & Şiddetli ağrı. Oral beslenmeyi bozmakta \\
\hline Evre 4 & Hayatı tehdit eder tarzda. Acil girişim şart \\
\hline Evre 5 & Ölüm \\
\hline
\end{tabular}

Enfeksiyöz Komplikasyonlar: Gerek oral mukozal bariyerin bozulması, gerekse azalmış mutlak nötrofil sayısı çeşitli bakteriyel, viral ve fungal enfeksiyonlara zemin hazırlar. Nötropenik hastalarda ve özellikle transplantasyon uygulanan hastalarda mukozit nedenli oral enfeksiyonlardan en sık rastlananı oral kandidiazistir. İkinci sıklıkta gözlenen enfeksiyöz ajan herpes simplekstir. Özellikle Otolog veya allogeneik kök hücre transplantasyonu uygulanan hastalarda mukozit derecesi ile sistemik bakteriyemi arasında direkt ilişki vardır. Öte yandan sistemik kandidiazis tespit edilen tüm hastalarda oral kandidiazisin de belirlenmesi kaynağın oral mukoza olabileceğini kuvvetle düşündürmektedir ${ }^{10-12}$

Yüzeyel orofaringeal kandidiazis topikal nistatin ile tedavi edilebilir. Genellikle sistemik tedavi gerektirmez. Dirençli olgular sistemik antifungal tedavi gerektirir. Profilaktik oral flukonazol genellikle önerilmekle birlikte profilaktik nistatin önerilmemektedir. ${ }^{12}$

Oral kavitede viral enfeksiyon da gelişebilir. Bunlardan en sık görüleni herpes simpleks tip 1 reaktivasyonudur. HSV enfeksiyonu daha ağır ve uzun süreli olma eğilimindedir. Bir çalışmada kemoradyoterapi sonrasında \%43 olguda oral herpes geliştiği bildirilmiştir. Özellikle HSV-1 seropozitif olup ağır mukoziti olan hastalarda asiklovir veya valasiklovir ile ampirik antiviral tedavi uygulanabilir. ${ }^{13}$

Akut lösemide remisyon indüksiyon tedavisi uygulanacak hastalar veya yüksek doz hazırlama rejimi ile kök hücre transplantasyonu uygulanacak hastalarda HSV reaktivasyonu yüksek sıklıkta görüleceğinden, kemoterapi ile birlikte oral veya parenteral asiklovir

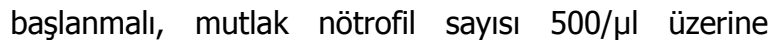
çıkıncaya kadar devam edilmelidir. Bu profilaksi semptomatik HSV enfeksiyon oranın \%70 den \%5-20 ye düşürür. ${ }^{14}$

Profilaktik ağız bakımı: Kanser tedavisinden önce çok dikkatli bir oral muayene önemlidir. Olası enfeksiyon odaklarının önceden belirlenip tedavi edilmesi enfeksiyöz komplikasyonları azaltır. Periapikal radyolusentlikler özellikle çürük varlığında enfeksiyon göstergesi olabilir ve periapikal enfeksiyon belirtileri varsa tedavi edilmelidir. Keza ağır periodontal hastalıkta diş ekstraksiyonu da uygulanabilir. ${ }^{15}$

Önleyici tedavi: Kemoterapi ile ilişkili mukoziti önlemek veya azaltmak için çeşitli stratejiler vardır. Ancak bunlardan çoğunun yararı sınırlıdır. ${ }^{16}$ Çeşitli kılavuzlarda hematopoetik kök hücre transplantasyonu öncesi yüksek dozlarda melfalan veya 5-fluorourasil uygulamasında oral kriyoterapi ve palifermin önerilmektedir. Özellikle bolus tarzda 5 fluorourasil kullanan hastalarda mukozit önemli bir sorundur ve çeşitli çalışmalarda oral buz uygulamasının vazokonstrüksiyonu uyararak kısa etki süresi boyunca bu ilacın oral yan etkilerinden koruma sağladığı gösterilmiştir. ${ }^{17,18}$

Her ne kadar veriler sınırlı olsa da kriyoterapinin yüksek doz melfalan uygulamasından sonra gelişen mukoziti de önlemede etkili olduğu bildirilmiştir.

Palifermin: Palifermin rekombinant keratinosit büyüme faktörüdür ve epitelyal hücrelerin proliferas- 
yonunu ve farklılaşmasını uyarır. Değişik çalışmalarda yüksek doz tedavi ve kök hücre nakli uygulanan hastalarda kemoterapi ile birlikte palifermin uygulamasının mukozitin ağırlığını ve süresini azalttığı gösterilmiştir. ${ }^{19,20}$

Lazer tedavisi: Hematopoetik kök hücre transplantasyonu uygulanan hastalarda tedavi öncesi helyum- neon lazer uygulamasının mukoziti azalttığı gösterilmiştir. ${ }^{21}$

Glutamin: glutamin, hızlı çoğalan hücrelerin nükleik asit sentezi için öncü bir aminoasittir. Parenteral glutamin tedavisinin mukoziti önlemede yararı kesin olarak gösterilememiştir. Oral glutaminin yayrı konusunda çelişkili bilgiler vardır. Oral glutaminin solublitesinin az olması nedeniyle düşük biyoyararlanımı olduğu ve bu nedenle yararın sınırlı olduğu öne sürülmüştür. Biyoyararlanımın daha yüksek olduğu oral L-glutamin formülasyonlarının mukozit ağırlığını azaltmada etkili olduğu kontrollü bir çalışmada gösterilmiştir. ${ }^{22}$

Diğer Ajanlar: Kalsiyum fosfat reçineleri, allopurinol ile gargara, hematopoetik büyüme faktörleri ve klorheksidin ile belli oranda fayda sağlandığına dair çalışmalar vardır. ${ }^{23-25}$.

Oluşmuş mukozitin tedavisi: Mukozit tedavisi destekleyicidir ve semptomlara yöneliktir. Oral bakım, topikal mukoza koruyucular, topikal ve/veya sistemik analjezik-anestezikler, E vitamini ve kapseisinin bazı olgularda semptomatik iyileşme sağladığı öne sürülmüşse de her bir ajanla ilgili veriler ya zayıf ya da tartışmalıdır. ${ }^{26-29}$

\section{KAYNAKLAR}

1. Epstein JB, Thariat J, Bensadoun RJ, et al. Oral complications of cancer and cancer therapy: From cancer treatment to survivorship. CA Cancer J Clin 2012; 62:400-22.

2. Krishna SG, Zhao W, Grazziutti ML, et al. Incidence and risk factors for lower alimentary tract mucositis after 1529 courses of chemotherapy in a homogenous population of oncology patients: clinical and research implications. Cancer 2011; 117:648-55.

3. Sonis ST, Elting LS, Keefe D, et al. Perspectives on cancer therapy-induced mucosal injury: pathogenesis, measurement, epidemiology, and consequences for patients. Cancer 2004; 100:1995-2025.

4. Robien K, Schubert MM, Bruemmer B, et al. Predictors of oral mucositis in patients receiving hematopoietic cell transplants for chronic myelogenous leukemia. J Clin Oncol 2004; 1;22:1268-75.

5. Sausville EA, Longo DL. Principles of cancer treatment. In Fauci AS, Braunwald $E$, Kasper DL, Hauser SL, Longo DL, Jameson JL, Loscalzo J, eds. Harrison's Principles of Internal Medicine, 17th ed. McGraw Hill Medical;2008; 514-33.

6. Barasch A, Peterson DE. Risk factors for ulcerative oral mucositis in cancer patients: unanswered questions. Oral Oncol 2003; 39: 91-100.

7. Sonis ST, Sonis AL, Lieberman A. Oral complications in patients receiving treatment for malignancies other than of the head and neck. J Am Dent Assoc 1978; 97:468-72.

8. Pratesi N, Mangoni M, Mancini I, et al. Association between single nucleotide polymorphisms in the XRCC1 and RAD51 genes and clinical radiosensitivity in head and neck cancer. Radiother Oncol 2011; 99:356-61.

9. National Cancer Institute Common Toxicity Criteria. http://ctep.cancer.gov/protocolDevelopment/electr onic_applications/docs/ctcaev3.pdf (Accessed on March 08, 2011).

10. Eisen D, Essell J, Broun ER. Oral cavity complications of bone marrow transplantation. Semin Cutan Med Surg 1997 Dec;16:265-72.

11. Ruescher TJ, Sodeifi A, Scrivani SJ, et al. The impact of mucositis on alpha-hemolytic streptococcal infection in patients undergoing autologous bone marrow transplantation for hematologic malignancies. Cancer 1998; 82:227581.

12.. DeGregorio MW, Lee WM, Ries CA. Candida infections in patients with acute leukemia: ineffectiveness of nystatin prophylaxis and relationship between oropharyngeal and systemic candidiasis. Cancer 1982; 50: 2780-4.

13. Elad S, Zadik Y, Hewson I, et al. A systematic review of viral infections associated with oral involvement in cancer patients: a spotlight on Herpesviridea. Support Care Cancer. 2010;18:9931006. 
14. Whitley RJ, Gnann JW Jr. Acyclovir: a decade later. N Engl J Med 1992; 327:782-9.

15. Djuric M, Hillier-Kolarov V, Belic A, et al. Mucositis prevention by improved dental care in acute leukemia patients. Support Care Cancer 2006; 14:137-46.

16. Saadeh CE. Chemotherapy- and radiotherapyinduced oral mucositis: review of preventive strategies and treatment. Pharmacotherapy. 2005 Apr;25: 540-54.

17. Mahood DJ, Dose AM, Loprinzi $C L$, et al. Inhibition of fluorouracil-induced stomatitis by oral cryotherapy. J Clin Oncol 1991; 9: 449-52.

18. Tartarone A, Matera R, Romano G, et al. Prevention of high-dose melphalan-induced mucositis by cryotherapy. Leuk Lymphoma 2005; 46:633-4.

19. Farrell $\mathrm{CL}$, Bready JV, Rex $\mathrm{KL}$, et al. Keratinocyte growth factor protects mice from chemotherapy and radiation-induced gastrointestinal injury and mortality. Cancer Res 1998; 58: 933-9.

20. Keefe DM, Schubert MM, Elting LS, et al. Updated clinical practice guidelines for the prevention and treatment of mucositis. Cancer 2007; 109:820-31.

21. Cowen D, Tardieu C, Schubert M, et al. Low energy Helium-Neon laser in the prevention of oral mucositis in patients undergoing bone marrow transplant: results of a double blind randomized trial. Int J Radiat Oncol Biol Phys 1997; 38:697703.

22. Peterson DE, Jones JB, Petit RG 2nd. Randomized, placebo-controlled trial of Saforis for prevention and treatment of oral mucositis in breast cancer patients receiving anthracycline-based chemotherapy. Cancer 2007; 109:322-31.

23. Papas AS, Clark RE, Martuscelli $G$, et al. A prospective, randomized trial for the prevention of mucositis in patients undergoing hematopoietic stem cell transplantation. Bone Marrow Transplant 2003; 31: 705-12.

24. Chi $\mathrm{KH}$, Chen $\mathrm{CH}$, Chan WK, et al. Effect of granulocyte-macrophage colony-stimulating factor on oral mucositis in head and neck cancer patients after cisplatin, fluorouracil, and leucovorin chemotherapy. J Clin Oncol 1995; 13: 2620-8.

25. Sorensen JB, Skovsgaard T, Bork E, et al. Doubleblind, placebo-controlled, randomized study of chlorhexidine prophylaxis for 5-fluorouracil-based chemotherapy-induced oral mucositis with nonblinded randomized comparison to oral cooling (cryotherapy) in gastrointestinal malignancies. Cancer 2008; 112:1600-6.

26. Hita-Iglesias $P$, Torres-Lagares $D$, Gutiérrez-Pérez JL. Evaluation of the clinical behaviour of a polyvinylpyrrolidone and sodium hyalonurate gel (Gelclair) in patients subjected to surgical treatment with $\mathrm{CO} 2$ laser. Int J Oral Maxillofac Surg 2006; 35: 514-7.

27. Wadleigh RG, Redman RS, Graham $M L$, et al. Vitamin $E$ in the treatment of chemotherapyinduced mucositis. Am J Med 1992; 92:481-4.

28. Cerchietti LC, Navigante AH, Bonomi MR, et al. Effect of topical morphine for mucositis-associated pain following concomitant chemoradiotherapy for head and neck carcinoma. Cancer 2002; 95: 22306.

29. Berger A, Henderson M, Nadoolman W, et al. Oral capsaicin provides temporary relief for oral mucositis pain secondary to chemotherapy/ radiation therapy. J Pain Symptom Manage 1995; 10:243-8.

\section{Yazışma Adresi}

Doç. Dr. İlhami KİKİ

Atatürk Üniversitesi Tıp Faültesi

İç Hastalıkları Anabilim Dalı Öğretim Üyesi

Blokları-ERZUrUM

Telefon: 442-2317183

Mobil telefon: 05354859000

e-mail: kikiilhami@yahoo.com 